\title{
Del latín al vascuence pasando por el navarro: sobre los topónimos navarros terminados en -áin
}

\author{
From Latin to Basque through Navarrese: On the subject \\ of the Navarresse toponyms ending in -áin
}

\author{
Fernando González Ollé \\ Universidad de Navarra \\ fgolle@unav.es
}

ORCID iD: https://orcid.org/0000-0003-3790-9149

RESUMEN: El hecho de documentarse en Navarra varios centenares de topónimos terminados en -áin (escasos, en el País Vasco) atrajo pronto (al menos, con autoridad, desde 1875) el interés etimológico sobre ellos. Son muchas las hipótesis formuladas, sin haber logrado una solución convincente. Ello se debe a que se ha entendido la citada secuencia final como castellano, cuando, obviamente, por su procedencia corresponde al navarro. Desde este nuevo enfoque, se propone su origen a partir del latín

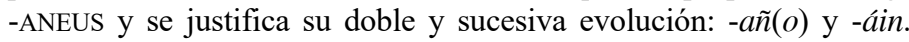

Palabras clave: sufijo -áin, dialecto navarro, toponimia vascuence, relaciones vasco-románicas.

ABSTRACT: The documentation of several hundred toponyms ending in -áin in Navarra (scarce, in the Basque Country) fast attracted (whit competece, as early as 1875) etymological interest in words containing this sequence. Many hypotheses have been proposed as to the form's origin, though no convincing explanation has been reached. This is because this sequence has traditionally been understood as pertaining to Castilian Spanish, when, obviously, it is as pertaining to Navarrese. From this new approach, the sequence's origin is proposed to be derived from the Latin -ANEUS,

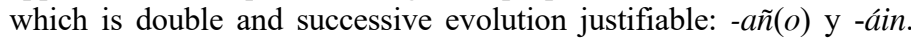

Keywords: -áin suffix, Navarre dialect, Basque Toponymy, Basque-roman relations. 
1. Los topónimos terminados por -áin ${ }^{1}$ se cuentan a centenares ${ }^{2}$ en ambas vertientes pirenaicas del área tradicionalmente adscrita al vascuence. Salaberri (2000) facilita una cumplida revisión de la copiosa bibliografía (unos 60 ítems, dése como exhaustiva) suscitada por ellos a lo largo de más de un siglo (en cabeza, el príncipe Bonaparte, 1875).

Los topónimos que examinaré de modo primordial (luego precisaré con exactitud el criterio de elección) son los formados sobre la base de un antropónimo, seguida "inmediatamente" ${ }^{3}$ del segmento -áin, para denominar entidades de población en Navarra. Mantengo así la extendida preferencia mostrada por los portadores actuales de -áin, sin duda como grupo homogéneo muy numeroso, si no mayoritario, dentro del léxico caracterizado por tal segmento.

Tal es el ámbito del presente estudio. Ocasión habrá, en otro momento, de aceptarse las propuestas obtenidas por él, de saber si cabe aplicarlas a orónimos, hidrónimos, etc., incluso a nombres apelativos ${ }^{4}$. Pues, según el estado de la cuestión, queda al descubierto que hasta ahora no se ha encontrado, si mi juicio es cierto, una solución satisfactoria suficientemente compartida para la procedencia de -áin. Este es mi objetivo primario, a través de una nueva vía.

2. Dentro de la extensa área léxica notada, Salaberri (2000) considera a Navarra "tierra típica de -ain". En una exposición detallada, establece cuatro

\footnotetext{
${ }^{1}$ Por razones de exactitud fonética, que coinciden con la ortografía española, doy preferencia a marcar siempre el acento en -áin, salvo en las citas, si no figura en ellas. Quizá convenga advertir que la ortografía vascuence no emplea tilde acentual, pero su empleo para conocer la pronunciación de los topónimos aquí estudiados resulta de primera importancia, hasta el punto de que las divergencias de esquema acentual pueden revelar una frontera ( $c f r$. Corominas, 1972: 307). No extrañe, pues, que la tilde figure a veces marcada en testimonios vascuences.

${ }^{2}$ La recopilación más extensa que conozco es la de Ramírez Sádaba (2002: 40-44), con casi trescientos ítems. Obviamente, no todos han sido analizados, por lo cual quizá quepa eliminar algunos. Como también estimo que sea posible incrementarla con otros.

${ }^{3}$ Muchos topónimos revelan, al menos en un primer examen, otro elemento entre la base y -áin. A veces, identificable con un verdadero segmento unitario e independiente de -áin. Un correcto análisis de sus constituyentes descubre que la base está primariamente prolongada por un componente al cual sigue el citado. El caso más frecuente de esta derivación (o composición) es el vascuence -gain, 'alto', 'altura', cuya identidad se dificulta si - $g$ - se sincopa: Abaurregain, 'Abaurrea alta' / Sasi(g)ain, sin relación léxica —ni idiomática, anticipo-, con -áin. Incluso cabría, otras veces, la posibilidad de un antónimo del citado, como -arana, 'valle', > -arain > -ain Tal, Baluriain < Baluriarana (Salaberri, 2000: 128). La polisemia atribuida en ocasiones a -áin (verdadero sufijo, para algunos autores: Michelena, Salaberri, Ramírez Sádaba y otros) y la discrepancia sobre su procedencia (latina o vascuence, con variadas propuestas para cada opción) suponen, en otro orden, dificultades añadidas.

${ }^{4}$ Por razones de espacio, apenas examinaré las bases derivativas (en número abundante, de segura condición antroponímica por lo general), las cuales con frecuencia han suscitado más interés que la secuencia final. Sin desentenderme de ellas, claro está, he de relegarlas, por ahora, a su condición de inevitable telón de fondo sobre el origen de -áin.
} 
grupos, según la afinidad de opiniones emitidas sobre su origen: 1) El genitivo vascuence de plural, -aren, por síncopa de - $r$ - y reducción del hiato consiguiente a diptongo. Parece ser la primera hipótesis emitida, a cargo del príncipe Bonaparte. Según Salaberri (para quien la evolución expuesta es moderna), cuenta con menos partidarios que detractores. Por mi parte, me permito enfatizar la temprana idea de posesión que encierra esta hipótesis: con el paso del tiempo, será el significado dominante en la bibliografía y a él se adhiere también mi propuesta. 2) El constituyente -(g)ain. Cuenta con bastantes adeptos. Destacados vascólogos lo aceptan para un número muy bajo de testimonios que acreditan su presencia. 3) Sufijo locativo. Sus valedores discrepan en cuanto a la precisa identificación dentro del vascuence. 4) El sufijo latino -ANUM, con base antroponímica y significado, también en esta opción, posesivo.

De esta última hipótesis como de otras posteriores relevantes, incluida la del propio Salaberri (2000) tras su revisión, me ocupo a continuación, paso previo a manifestar mi opinión.

3. La investigación sobre el origen de -áin se reanimó merced a una propuesta de Caro Baroja o, mejor, por las réplicas, negativas, variadas y contradictorias, que suscitó. Según Caro (1945: 63), "el fundus ha pasado de mano en mano, pero conservando su nombre primitivo y su estructura, es decir, sin cambiar el nombre del primer dueño ${ }^{5}$, a efectos de su identificación en los registros públicos".

En una transformación social compleja, se convertiría en vicus, 'aldea', a fines del siglo III, ante las invasiones bárbaras. La existencia en varias áreas románicas de topónimos cuya formación responde a derivados con -ANUS, le lleva a postular este sufijo latino como antecesor de -áin. Con tal terminación, recoge un elenco de topónimos (Caro Baroja, 1945: 67-76), cuyos étimos antroponímicos establece con distintos grados de seguridad (Ibíd.: 86-89).

Precisamente en una monografía sobre -anus, escribe su autora, latinista (Morano, 1978: 760): "En la época más antigua fue una costumbre general en latín sustituir los topónimos de sustantivo por adjetivos derivados de los mismos, luego sustantivados. Una costumbre que sobrevivió en el paso del latín a las lenguas romances".

Tal sería el caso de Nomentum $\sim$ Nomentanum, Lucus $\sim$ Lucanus, etc.

Caro Baroja no andaba, pues, descaminado. Pero su propuesta ("mi punto de vista es histórico-cultural tanto o más que lingüístico, para no hacer del vasco un Robinson, como ya es", reconoce), aun aceptada por Gavel (1951) y

\footnotetext{
${ }^{5}$ A idéntica suposición se llega, independientemente, desde la sintaxis latina, como luego expondré.
} 
Gorrochategui (1995), no era aceptable desde el obligado enfoque, obviamente, lingüístico. El rechazo resultaba previsible, como efectivamente sucedió ${ }^{6}$.

4. Si mi dato es cierto, por primera vez se ocupa Michelena de la secuencia -áin en la edición príncipe de su Apellidos vascos (1952), donde la considera "un sufijo que en algunos casos puede representar una variante de -gain", con aportación de varios testimonios. En estudios posteriores mantendrá la estimación de -áin como sufijo.

Michelena (1955 [1952]) vuelve sobre el mismo asunto dos años después, para apuntar que "el sufijo -ain aparece en una zona Navarra como -in, en suletino como -ein, -eñe; también en Álava, Andoin, en 1025 Anduiahin. Un caso muy conocido de -ain > -in es Larrañaga, Larrinaga, vasc. larrain, larrin, 'era', acaso un préstamo".

Con máxima densidad en torno a Pamplona encuentra gran número de poblaciones con nombre terminado en -áin, cuyo primer componente es un antropónimo. La comparación con topónimos de Vasconia terminados en -ano (-ao, - o en Vizcaya y Guipúzcoa) hace inevitable la presunción de que el sufijo -ain es también un representante de -anu. Sin embargo, por consideraciones puramente lingüísticas ${ }^{7}$, la terminación se reconstruiría como ${ }^{*}$-ani o *ane: Badoztani, en 1037.

Hasta la tercera edición de su obra no rehace Michelena (1973 [1952]: 38-40) el pasaje reproducido, con una innovación radical, si bien anticipada parcialmente en 1955, de hondas repercusiones en los tratadistas de la materia.

Michelena empieza su explicación aceptando la de Caro Baroja. Dado que "proporciona un gran número de etimologías completamente satisfactorias, no puede ser puesta en duda en cuanto a su corrección, teniendo en cuenta que la dificultad fonética (- $a n u$ ha dado normalmente $-a u(n))$ se salva admitiendo una pequeña modificación en las ideas de Caro Baroja".

La "pequeña modificación" introducida resulta, si se valora apropiadamente, una verdadera enmienda profunda: solo por deferencia hacia Caro Baroja cabe entender que Michelena minusvalore su innovación: "Como ha mostrado J. M. Piel («Nomes de possessores latino-cristâos na toponímia asturo-galego-portu-

\footnotetext{
${ }^{6}$ Caro Baroja (1958) se valió de un artículo (reproducción de una conferencia: no consigna más datos) para mostrarse indignado ante la repulsa de su tesis por parte de Hubschmid y de Fouché, durante un congreso de toponimia (no precisa cuál). Caro parece desconocer o no admitir la acreditada competencia de ambos lingüistas. A la objeción presentada por ellos: el resultado de -ANUS sería en vascuence $-a(n) u$ (como efectivamente sucede, cfr. § 4), respondió con airados juicios denigratorios sobre la validez de las leyes fonéticas.

${ }^{7}$ La calificación puede parecer obvia. No lo es en cuanto que Michelena, como luego explicito, trata de atemperar delicadamente su despego de la consideración cultural de Caro Baroja.
} 
guesa», Coimbra, 1948) ${ }^{8}$, la toponimia hispánica muestra la generalización del tipo villa Aemilii, reducido muchas veces al genitivo Aemilii"’.

5. Compendio, muy simplificada, la propuesta de Piel, punto de partida del giro operado por Michelena (1973 [1952]).

Piel estudia las más antiguas formaciones de los deantropónimos procedentes de época romana, también las registradas durante la Reconquista, las más numerosas, forzadas por el cambio de propietario y, en consecuencia, con la necesidad de otorgarles nueva denominación.

Según Piel (1948: 152), el sistema inicial de designación solía basarse en el nombre del propietario, en función adjetival, con variación formal de género, si era precisa: Villa Aemilia. También, mediante la derivación adjetiva del antropónimo por medio del sufijo -anus (masc.), -ana (fem.): Villa Aemiliana. La expresión más corriente adoptará el genitivo del poseedor: Villa Aemili $(i)$ o simplemente Aemili(i). Este último uso, genitivo con valor posesivo ${ }^{10}$, se presenta como casi exclusivo de Hispania, ausente en cualquier otra zona románica. Su generalización comienza en época sueva, visigoda y altomedieval, es decir, diversa según regiones. Así, los topónimos gallegos procedentes de antropónimos derivados mediante -anus, -ana se tienen por pertenecientes a época romana (siglos I-IV d. C. $)^{11}$.

Cuestión aquí de suma prestancia es el empleo de genitivo $(-a e,-i,-i s)$ para el nombre del poseedor, según acredita Piel con abundante documentación del proceso onomasiológico en su aspecto sintáctico (genitivo)-semántico (antropónimo) ${ }^{12}$.

${ }^{8}$ En el prólogo a la segunda edición de su libro, Michelena (1955 [1952]) declara que el estudio de Piel le ha servido de "extraordinario provecho". En efecto, su conocimiento le permitió iniciar una nueva vía y suprimir el asterisco que había colocado ante *-ani (Michelena, 1988 [1956]: 576). Sorprenderá, sin duda, que no haya incluido tal supresión en la primera obra aquí consignada, vista su precedencia temporal. El patente desajuste deberá juzgarse a la luz de la contradictoria información que Michelena proporciona en el mencionado prólogo sobre los avatares de ambos estudios. Según sus palabras, la segunda edición de Apellidos vascos estaba "ya compuesta cuando salió a luz el libro una "Introducción fonética a la onomástica vasca" que por distintas razones no se ha publicado hasta ahora. Hoy puedo remitir a ese trabajo, que no tardará en aparecer". El anunciado libro no llegó a publicarse, que yo sepa. El título indicado corresponde a un artículo aparecido en Emerita (Michelena, 1957).

${ }^{9}$ Anoto. Bermuy, pueblo de Coruña y de Segovia, al menos, procede de Bermu(d)i, genitivo de Bermudus, obtenido por adaptación del antropónimo germano a la flexión latina y su posterior evolución romance.

${ }^{10}$ En la medida en que desaparece la flexión casual, el genitivo es remplazado por la forma nominal única, generalmente acompañada de la preposición de.

${ }^{11}$ Pocos años después, Piel (1954: 248) reitera y enriquece esta doctrina: "La mayoría de los topónimos germano-hispánicos no provienen de la época de la monarquía visigoda, sino que surgieron en el trascurso de la reconquista y población de las tierras del noroeste". Atiende también a los nombres germánicos para mostrar la generalización del esquema derivativo.

${ }^{12}$ Alperiz (gen. de Hilpericus < HiLPAREIKs); Aragunde (gen. del fem. ARAGUNDIA > Aragonza (comp. con VERECUNDIA > vergüenza); Gulanes (gen. de *Golla, Gollanis); Gusley (gen. de GUDESLEUS). Etc. 
6. Las observaciones de Piel no encerraban originalidad alguna, dicho sea sin el menor detrimento de sus valiosas aportaciones a la toponimia hispánica. Mostraban de modo patente la continuidad del sistema onomasiológico latino en Hispania. Importa tener presente su conocimiento, muy simplificado en mi exposición, antes de considerar su modo de aplicación por Michelena, puesto que declara haberse inspirado en el estudio de Piel.

Michelena lo ensaya en varios topónimos terminados en -áin. "Así se explican nombres de poblaciones navarras (y de zonas vecinas, entre las cuales se cuenta la Soule) como Amalain (Aemiliani), Amatr(i)ain (Emeteriani) [...], Astrain (ant. Azterain, de Asteriani)". Al llegar aquí la enumeración prosigue sin solución de continuidad con otros topónimos de la misma terminación, ahora acompañados por sendos nominativos latinos: Barbatain (Barbatus), Domezain (Domitius), Maquirriain (Macer), Paternain (Paternus), etc. ${ }^{13}$

7. La exposición de Michelena incurre, a mi entender, en una evidente inconsecuencia (con pronta y extendida repercusión en investigaciones ajenas) al aplicar el modelo ("genitivo Aemilii") descrito por Piel: la exigencia del genitivo adnominal posesivo, el requerido sintácticamente por el nombre propio del poseedor (y no por el de su derivado adjetival), ha sido desplazada hasta el genitivo del adjetivo deantroponímico. Así se observa, por ejemplo, cuando Michelena propone el étimo de Amalain: el genitivo Aemili (cfr. supra) ha sido suplantado, como base derivativa, por el "genitivo latino -ani", correspondiente a Aemiliani, es decir, el "derivado adjetival" del nombre personal del propietario, mediante el sufijo -anus. Del mismo modo procede Michelena con los demás topónimos: Emeritani, para Amatr(i)ain; Asteriani, para Astrain; etc. Proceso independiente es el paso, con el tiempo, de algunos, pocos, de estos adjetivos a nombres personales. $\mathrm{O}$, si prefiere, de cognomen a nomen.

En conclusión. Michelena funde en uno solo — si entiendo bien- dos procesos alternativos: genitivo adnominal del nombre personal (nomen) del propietario, o derivado adjetival (cognomen) desde él, mediante -anus. Tal fusión conduce a una secuencia agramatical, inviable, por tanto, como punto de parti-

\footnotetext{
${ }^{13}$ Sin ningún comentario, Michelena menciona el antropónimo "Scemen Baterne $<$ Paterni, Valb. 191, a. 1108" (debe de remitir a la documentación del monasterio de Valbanera, en La Rioja, documento n. ${ }^{\circ} 191$ a(ño o anterior a). 1108. Con Baterne parece que Michelena quiere ejemplificar la conservación y evolución normal de un genitivo antroponímico (equivalente a los testimonios aducidos por Piel), de acuerdo con la fonética vascuence, en cuanto a las dos primeras consonantes; con la romance, en cuanto a la vocal final. Consta la existencia de Paternina y Baterne, como apellidos; de Baterna y Paterna, como poblaciones, respectivamente, de Ávila (donde la consonante inicial, $B$-, acusa la fonética árabe) y de Valencia; Trespaderne, de Burgos. Etc. Cfr. Paternáin, § 16.
} 
da. Queda patente que, según las pautas propuestas, resultan secuencias válidas, perfectamente gramaticales, tanto fundus Centulli como fundus Centullianus, pero no *fundus Centulliani.

8. Si mi observación se estima pertinente, deberá concluirse que la explanación más asentada sobre el origen de -áin parte de un error sintáctico ${ }^{14}$, fruto quizá de una redacción apresurada ${ }^{15}$, con poca fortuna, que deja indecisa la cuestión.

A su anterior exposición añade Michelena que "la explicación de -ain a partir del genitivo latino -ani valdría para la Soule, pero no para la Navarra Alta, donde desde los primeros testimonios, el resultado único de ant. *-ani es -ai, sin rastro de nasalidad".

Varias afirmaciones de la mención de Michelena recién citada me resultan desconcertantes: la exclusión de la Navarra Alta (denominación secular de la Navarra española o peninsular frente a la Baja Navarra ${ }^{16}$, que corresponde a la Navarra francesa o continental), puesto que previamente había situado -áin en la Navarra española. Por el contrario, repite innecesariamente la inclusión de Soule. Esta incoherencia viene a confirmar mi anterior hipótesis sobre la momentánea distracción de Michelena durante la escritura o una precipitada redacción, nunca revisada.

Más. No se ve cómo el étimo propuesto, -ani, evolucione (cfr. supra la opinión del propio Michelena ${ }^{17}$ ) a -áin, se lea como se lea (cfr. § 14) ${ }^{18}$. Así lo ha ratificado puntualmente, como luego expongo, Salaberri ${ }^{19}$, con superior competencia a la mía. A su vez, en romance, -ani hubiera abocado a an(e).

9. Sobre los topónimos con que titula su estudio cree Irigoyen (1987: 201) que "a veces puede tratarse de simples formas de persona con sufijo [?]

${ }^{14}$ Las variantes dialectales de -ain, estudiadas también por Michelena (1976 [1961]: 66 y 189), no afectan a la cuestión tratada, pero, sorprendentemente, no menciona -ani.

${ }^{15}$ Como prueba la frase "a su lista puede hacerse alguna adición", cuyo más próximo referente, Lacarra, citado en un período anterior, no establece una lista de topónimos en -ain.

16 "País de Navarra la Baja o francesa" (Yanguas, 1840: I, 46).

${ }^{17}$ En el ya mencionado prólogo a la segunda edición, 1955, de su libro Michelena, con toda modestia, reconocía: "Me doy cuenta de que un grave defecto de esta obra está en que en ninguna parte expongo mis ideas sobre la evolución de los sonidos vascos".

${ }^{18}$ Que yo sepa, solo para Ramírez Sádaba (1988: 188), desde *Floriani, *Barbatani, etc. "es perfectamente explicable la evolución -ani > -ain, en virtud de las leyes propias de la lengua vasca, como ocurrió con abundantes términos de su propio léxico" (?).

${ }^{19}$ La irreprochable aplicación en varios de sus estudios ( $c f r$. infra) revela la excepcionalidad de diversas fases evolutivas si se parte desde -ani. Aunque, por tanto, declare su disconformidad, se comprende bien su mesura: había de resultarle improcedente — sentimiento que comparto- la desaprobación de un maestro como Michelena. 
-ani, no en caso genitivo [¿alusión a Michelena?] ${ }^{20}$, sino doblete [?] de -ano < $-a n u$, lo que es normal en la antroponimia latina, e incluso autóctona posterior".

Para él, -ani es un nominativo, de acuerdo con Väänänen (1967: 180): "El vocativo se confunde con el nominativo ${ }^{21}$, sobre todo en la aposición". Irigoyen (1987) aduce los nombres de una inscripción africana, 359 d. C.: Datiani, Donatiani, Cipriani, Nemesani. Pero el ir encabezados por un genitivo de plural marturum ${ }^{22}$ debilita un tanto, en mi opinión, la posibilidad de que sean verdaderos vocativos (nominativos) y apunta, por el contrario, a su condición de genitivos (apositivos). Como sí lo son, según el mismo Irigoyen (1987: 201), los dos últimos, [C]itini et Victo[r]ia[i]s. Estimo razón insuficiente, si no acomodaticia, para diferenciarlos de los precedentes, el no terminar, a la par de ellos, en el requerido -ani y, por tanto, excluirlos.

Como ejemplos medievales, Irigoyen (1977) aporta Garceani, rex in Papilona, y Garseani, episcopo (Valpuesta, año 1035), más su doblete, regnante rege Garsiano (Irache, año 958) 23.

Estimo complicada, sin suponer avance alguno, la novedad gramatical ofrecida por Irigoyen (1977). Partir de ella encierra, obviamente, idénticos problemas que la de Michelena.

10. Tras su revisión bibliográfica, Salaberri (2000: 126) acoge, con serias reservas, que indicaré, la tesis de Michelena: "El origen está en el genitivo latino, es decir, en el sufijo que en un principio expresaba posesión, fuera de un fundus, un vicus o una villa, o fuera indicación de descendencia (hijo, hija de)".

En artículos posteriores, Salaberri (2011, ampliado en 2014, y 2012) remite al inicial (2000: 127) para ratificar que el étimo de -áin no está totalmente aclarado:

A pesar de que el origen de muchos de los topónimos en -ain es sin duda antroponímico, todavía hay varios puntos que no están nada claros [...]. En el caso de -ain en -ani, a pesar de que posteriormente estas terminaciones

${ }^{20}$ Anoto. Sobre la amplia presencia del genitivo en la antroponimia había advertido Michelena (1988 [1956]: 2, 603). Destaco su conclusión: "En territorio de habla vasca, donde los continuadores de lat. Sempronium y Semproni, etc., se confundían al parecer normalmente, la confusión del nombre con el patronímico puede explicarse sin mayor dificultad". Para testimonios de genitivo por nominativo en la antroponimia asturiana, Kremer (1990).

${ }^{21}$ Anoto. Abundantes ejemplos, tempranos y tardíos, de esta confusión, que alcanza a otros casos de la flexión, en Löfsted (1956b [1928]): 102-106.

${ }^{22}$ Como marturu figura en el texto aportado por Irigoyen. He comprobado directamente su fuente, CIL, VIII, 20600, que garantiza la corrección introducida por mí. En cuanto a la $u$ interior, recordaré que alternaban martyr, martyris, y martus, marturis.

${ }^{23}$ Aplica idéntico criterio al topónimo navarro Luquin (variantes antiguas, Luquiain, Luquiayn, Luquayn), procedente de un prototipo, *Lukiani, con sufijo -ani, doblete de -ano, "sin que, bajo el punto de vista del desarrollo histórico, tenga que ver necesariamente con el genitivo latino". 
cobraran autonomía y se añadiera a temas no latinos, en una época en que el sistema de declinación de esta lengua había desaparecido [...], la objeción de Mitxelena respecto a la evolución -ani > -ain en zona donde encontramos *-zani $>$-zai- perdura y no sabemos cómo superarla.

Con renuncia a resolverla, Salaberri (2012), en la exposición más completa de sus ideas, procede con cautela y rigor a identificar el sufijo en varios topónimos alaveses, "ya que los nombres en -ain no suelen presentar, en otras regiones, aspiración, lo mismo que -ano, -ana. En el caso de Navarra esto no es de extrañar, puesto que la pérdida de la misma fue temprana".

Salaberri (2012: 325n2) reitera que "en un momento determinado de la historia la terminación se independizó y fue empleada como sufijo productivo al menos en zona navarra de lengua vasca, tal como demuestran topónimos del tipo de Gartzain, Urdiain o Zuriain, basados en Gar(t)ze, Urde y Zuri'.

Únicamente él ha puntualizado los pasos requeridos desde el segundo modelo de Michelena hasta el previsto final. Los consigno, apenas simplificados.

La evolución de Agurain (Hagurahin, año 1025) habría sido: *Hagurani > *Hagurâhi $>*$ Hagurâhî $>*$ Hagurahî $>$ Hagurahin $>*$ Hagurain $>$ Agurain . Salaberri sospecha que esta última forma, sobreviviente, responda a una reinterpretación de la citada antigua, Hagurahin, cuyo "antropónimo de base tendría que ser algo como *Hagur(V)". Aduce, siguiendo a Mitxelena (1976: 301), que en vascuence, la pérdida de la nasal intervocálica suele acarrear la nasalización de la vocal anterior, no la siguiente. En consecuencia, para justificar las alternativas dialectales con final en $-\phi /-n$, postula una evolución tal como *usani > *usâi > *usâ̂ > usâ̂ > usai / usain.

No esconde Salaberri los problemas que comporta "explicar la $<\mathrm{h}>$ intervocálica de modo adecuado", dificultad común a otros topónimos de idéntico final. Cabría aceptar *ahi por residuo de la nasal de -ani, pero

resulta bastante más peliagudo admitir que, además de dejar como rastro una aspiración, nasalizó la vocal anterior, luego se produjo una asimilación progresiva y después una disimilación, y que, para terminar, la vocal palatal final nasalizada hizo surgir una consonante nasal $\left(-a n i>*_{-} \hat{a h} \hat{\imath}>*_{-a h \hat{\imath}}>\right.$ ahin).

Ante tales inconvenientes, propone otra solución. Si se admite, "por razones no claras", que "la aspiración no era etimológica" (es decir, surgida tras el acento, no en la sílaba tónica (*Haguráin, como Barañáin, Gartzáin, etc.), el proceso habría sido: -ani > -ain > -ahin (Salaberri, 2012: 326).

Según anticipé, sopesadas las graves anomalías de varias fases del proceso, Salaberri pone en entredicho la validez del planteamiento de Michelena. Ni -anus, ni -ani (genitivo o nominativo) se justifican, sea en vascuence o en romance. Subsiste el problema. 
11. Por su parte, tampoco la propuesta de Piel (cfr. § 5) sobre el nombre individuado del propietario de un bien rústico supone ninguna innovación metodológica: examina la toponimia del noroeste peninsular con los dos recursos propios del latín en este ámbito, genitivo adnominal y adjetivo de relación posesiva $^{24}$. Expongo algunas opiniones, muy selectivas, sobre la cuestión.

La función posesiva del genitivo en latín nunca se ha puesto en duda. La del adjetivo, admitida por varios autores desde los orígenes de esa lengua, generalmente con restricciones, sufre rechazos respecto a su indicación estricta de posesión $^{25}$.

Anticipo ya una relevante coincidencia con los topónimos en -áin. Wackernagel (1908, apud Löfstedt, 1956a [1928]: 107) mostró que los testimonios menos dudosos de propiedad mediante adjetivo derivado del nombre del poseedor ocurren para denominar bienes rústicos ${ }^{26}$.

Sobre la base derivativa, prosigue Wackernagel: "Lässt sich die Prioritat nachweisen. Wichtig sind in dieser Hinsichit eine Rehie alter Bildungen aus Namen von Personen, Göttern, Lokalitaten, etc." documentado con Venerius nepotulus, pars Herculanea, mensis Martius ${ }^{27}$.

La expresión de plena posesión advino tiempo después al adjetivo: uilla Pompeiana, uilla Ciceroniana, construcción pronto extendida a toda la latinidad, y vigente en el Medievo, para expresar la relación de una finca con su propietario $^{28}$, Aurelianus, Sabinianus (desde Aurelius, Sabinus).

Hasta aquí Wackernagel, mientras que Löfstedt (1956a [1928]: 109 y ss.), opuesto a la precedencia del adjetivo respecto al genitivo, distingue entre posesión estricta y lata. El adjetivo adquiere la primera por desvíos poéticos anor-

\footnotetext{
${ }^{24}$ La competencia entre ambos cuenta con un siglo largo, al menos, de estudios vigentes, enraizada en su debatida prioridad histórica, aún abierta, dentro de la lingüística indoeuropea. Coincidencias y divergencias funcionales y semánticas (manifestadas particularmente en nominación de villas, campos, etc.) difieren según cada lengua, y aun dentro de una misma lengua. Así ocurría en latín, como a continuación documento.

${ }^{25}$ Marouzeau (1970: 219) aporta una excelente prueba de la distinción: Fedro, a propósito de sus "propias fábulas", cuyo motivo toma de Esopo, se vale de esta alternancia para precisar la apuntada distinción: Aesopias, non Aesopi nomino.

${ }^{26}$ Con la salvedad de no asegurar si la mención corresponde al actual propietario, al inicial o a uno posterior.

${ }^{27}$ Estima caso notable de la alternativa, en Cicerón, ostium Oceani frente ostium Tiberinum, más ajustada la segunda opción al uso coloquial antiguo. Browse WordReference $(<\mathrm{http}: / /$ www.wordreference.com/es $>$ ) me depara una serendipia más neta aún: Ciceronis cliens (Seneca Rhetor, Controv. 7.2.11) Ciceronianus cliens (7.2.12). También, Domum Ciceronis (Cic. Pro domo sua, 133.3) Uilla Ciceroniana (Aelio Espartano, De uita Hadriani, 25.5.1).

${ }^{28}$ Uso no insólito, pues la relación entre dos substantivos solía expresarse en latín por la conversión adjetival de uno, medio suficiente para indicar dominio. Desde él se ofrecía la posibilidad de configurar un topónimo, como sucedió en muchas poblaciones del Imperio, cuyo nombre actual se origina según el modelo sintáctico recién explanado.
} 
males. Aunque la indicación posesiva reside, con mayor frecuencia de la que suele admitirse en testimonios antiguos de deantropónimos, estos no expresan originariamente un neto sentido de propiedad: "Nur der Genetiv wirkliches individuelles Besitzverhältnis ausdrückt, das Adjektiv dagegen mehr allgemein die Art, die Benennung, die Herkunft bezeichnet".

Previamente había declarado que "das Verthaltnis zwischen dem abgeleiteten, possessiven Adjetiv (erilis filius) und der possessiven Genetiv nach verschiedenen Richtungen hin skizziert" (Löfstedt, 1956a [1928]: 107).

12. Muy distinto juicio emite Mohrmann (1961 [1948]: I, 171). Ante sintagmas como calix Dominicus, passio Dominica, propios del latín cristiano y del tardío, sostiene la vigencia de un verdadero adjetivo de posesión ${ }^{29}$. Para ella, “en l'emploi de l'adjectif derivé nous constatons une difusion très large. On peut signaler une certaine prédilection pour l'emploi de l'adjectif au lieu du génitif adnominal dans toutes les périodes de la latinité chrétienne".

Esta última comprende desde Tertuliano y las Passiones martyrum (que transcriben sus actas procesales) hasta san Agustín, tanto en su prosa cultivada (De civitate Dei), como en la vulgar de sus sermones. Tal tradición, continuada por el adjetivo derivado, ajeno al empleo artificial supuesto por Löfstedt, afecta a todos los registros lingüísticos (Schrijnen, 1981 [1932]): Dominica passio es 'la pasión del Señor'; Evangelica parabola es 'la parábola del Evangelio'. Idéntica función posesiva ejercen también adjetivos derivados de nombres locativos y personales, de sumo interés aquí por su inmediata aplicación: Ecclesia Romana, Paulinus Nolensis, Deciana persecutio, sucesores directos de los antiguos Cannensis clades, colonia Agrippensis.

En fin, el uso adjetival (Mohrmann, 1961 [1948]: I, 172) constituye "une construction vraiment latine qui, tout en se basant sur des tendances anciennes de la langue, s'est développée indépendantement d'exemples étrangers" ${ }^{\text {" }}$.

13. Me detengo para mostrar cómo varios manuales recientes de sintaxis latina resumen la alternativa expuesta.

A propósito de Campus Martius, Martia regio, etc., comenta Touratier (1994: 200), en línea con Wackernagel:

${ }^{29}$ Löfstedt (1956a [1928]: 118-119), como cabía esperar, estima dies Dominica o Dominica dies uso extraordinario, enfático, para realzar su importancia religiosa frente al normal de genitivo en dies Domini.

30 Anoto. Tal independencia (respecto al griego, en cuyas construcciones con adjetivo derivado algunos autores ven el modelo temprano de su equivalente latino), se observa, por ejemplo, cuando la Vetus Latina ofrece Dominica (vasa) por kupiou, en la Biblia de los Setenta. Los poetas cristianos, al rehusar, en el stylus sublimis, las expresiones antes comentadas (passio Dominica), confirman indirectamente la generalización de la derivación adjetival. 
Par contre, ce qui concerne à la personne même et non pas seulement le nom ou les attributs de ces divinités ou de ces personnages recevra un complément au génitif. On dira Aedes Martis, parce qu'il s'agit de la demeure du dieu lui-même, et pas simplemente d'un lieu qui a reçu son nom ou qui a un rapport indirect avec lui.

Según Tarriño (2009: 264), con referencia a Caesaris militibus (César) militibus Caesarianis (Valerio Máximo), "los adjetivos que presentan esta alternativa son siempre derivados de nombres propios (Caesarianus, Fabianus, Saturnianus) o de referente humano (paternus, fraternus, regius, seruilis, etc.)".

Es decir, remiten a un participante de situación nominalizada en el SN.

Torrego (2009: 158) considera el genitivo caso asemántico, marca puramente relacional, sin explicitar su tipo, en el SN. Bajo él subyacen relaciones con otras formas de complementación. La más inmediata, el adjetivo posesivo: De summa salute uestra populique Romani.

Estos últimos testimonios (cfr. también Morano, 1978: § 3) confirman, como vengo reiterando, la vigencia, prácticamente en todo tiempo ${ }^{31}$, de los dos recursos principales que actualizaba el latín para expresar posesión: genitivo adnominal del nombre del poseedor o su derivado adjetival.

14. He detallado la función del sufijo -ANUS para justificar los autorizados motivos $^{32}$ que asisten a cuantos lo han incluido en el étimo de -áin. Su tenaz aceptación había llegado a formar una larga tradición ${ }^{33}$. Ella ha sido, en buena parte, la causa de no haber logrado el éxito merecido: estaba lastrada, a mi parecer, por el desvelado error (cfr. $\S 8$ ) de su punto de partida.

Se impone, via remotionis, desechar la secuencia -áin, si es leída, según ha ocurrido de modo generalizado, "como perteneciente al sistema gráfico del español" (actual o medieval, da lo mismo): representación de un diptongo decreciente (vocal $a$, semivocal $i$ ), seguido por una consonante nasal alveolar. Cuando, en verdad, sabidas con certeza la localización y antigüedad de sus testimonios, más, ante todo, la lengua de su transmisión, tal secuencia "debía haberse leído como navarro". Por tanto, representación de la vocal a seguida del dígrafo in, correspondiente a la consonante nasal palatal. Es decir, los topónimos terminados en la escritura por -áin presentan la secuencia fónica /ar/.

\footnotetext{
${ }^{31}$ Continuada hasta el español actual, como documento con un texto contemporáneo (Álvarez Rodríguez, 2016): Testamento de Genadio (17 y passim) testamento genadiano (20 y passim); obra de Sandoval (21 y passim) forma sandovaliana (29 y passim).

32 Ciertamente, -ANUS, -ANA figuran en la toponimia navarra, conservada o perdida la $-n$-, según la distinta tradición idiomática o normativa: Baquedano, Fustiñana, Galdeano, Labia $(n) o$ (ast. Llaviana < FlaVianA), Otiñano, Zoli(n)a, etc.

${ }^{33}$ Quizá haya influido también su aparente semejanza fónica con -ani ("los nombres de las poblaciones navarras en áin no tienen variantes sin -n”, Michelena, 1976 [1961]: 144n11).
} 
Queda así patente cómo el error inicial invalida estudios plausibles: buscaban aprehender una realidad inexistente ${ }^{34}$.

15. Comienzo la via positionis con una muestra de las grafías para $/ \tilde{\mathbf{n}} / \mathrm{de}$ varios textos medievales navarros:

Documentación de Leire (años 842-1201): aniulo (< AGNULUM), anniula (< AGNULAM); castange (<CASTANEUM); connato (< COGNATUM); Domeyno $(<$ DOMINIUM, actual top. Domeño); empeynnare (< PIGNORARE); Mainero, Manneru ( $<$ BALNEARIUM, actual top. Mañeru); pingora (< PIGNORA); seynor, seynior; uinga ( $<$ VINEAM).

Documentación de Irache (años 958-1397): doña; empeinnar, empeygnar; Irunga (actual top. Iruña); Maniero (< BALNEARIUM, actual top. Mañeru); Marangon, Maranion (actual top. Marañón); seygnorio; signno.

Liber regum (Cooper, 1960): anno; compannero; Espanna; montanna; sennal; sennor.

Vidal Mayor (Canellas, 1956): acompaynnamiento; ataynne; aynno; compaynna; empaynno; engain, engayn, engaynn, engaynna, engaynno, enguaynno; estaynno; engeynno; paynno.

Fueros de la Novenera (Tilander, 1951): aynno; caynna.

Fuero General de Navarra (en sus varias versiones, Gago Jover, 2013): adaynnar; ayno; bayno; cabayna, cabaynna; dayno, daynno; engaynn, engayno; estayno; remaynga; tamaynno; taynga.

Crónica general de España, García de Eugui (1907-1908 [mediados del s. XIV]): astayno, estaynno, stayño, staño; Bretayña, Bretanja; estrayño.

Variantes recogidas: in, ing, inng, gnn, $n g, n i, n j, n n, n n i, \tilde{n}, y g n, y n, y n i$, $y n n, y \tilde{n}^{35}$. Como enseguida se verá, los topónimos en -áin testimonian varias de estas terminaciones ${ }^{36}$, que así avalan la presencia de nasal palatal ${ }^{37}$.

Para Michelena (1988 [1956]: 576n16), que la pronunciación real de -ain

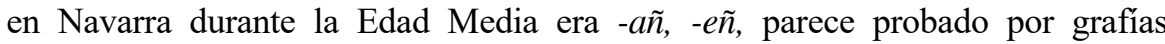

${ }^{34}$ Por otra parte, en ellos (los reseñados por Salaberrri, 2000) se suelen analizar sus bases según el trato dado por el vascuence a los latinismos. Pero no debe prejuzgarse que ocurriera así en todos.

${ }^{35}$ En textos languedocianos: $n,(i) n, n i,(i) n n,(i) i n g$, ingn, (i)nh, (i)gn, (i)nh (Grafström, 1958: 212-213).

${ }^{36}$ Añádanse topónimos en $-n h$, que luego cito en varios pasajes, procedentes en su mayoría de una fuente foránea, Rationes decimarum Hispaniae (1279-1280), dos libros de colecturía, cuyo editor (Rius Serra, 1947: VI), los atribuye a B. Vessiamo, clérigo provenzal, notario real de Aragón. A su origen achaca "el uso del grupo nh para un sonido igual o parecido a la eñe actual".

${ }^{37}$ Cierto que el nav. ofrece idéntica lectura que el cast. para la secuencia -áin en palabras de otro origen, como aína < AGINA, común a ambos. En vasc., orain, 'ahora' (según el DGV/OEH, parece proceder de lat. hora + demostrativo vasc. aen (comp. cast. ahora < HAC HORA), con múltiples variantes, según dialectos, que suelen perder $-n$; solo dos la palatalizan. En secuencia similar, para oinez, 'a pie', coexisten ambas pronunciaciones. 
como Badozteng (año 1110), Indurange (1064) [...], resultado normal de *-ani: en el siglo XII tenemos asegurado "piscem vocant araign" ${ }^{38}$, es decir, arrañ, de arrani.

Años después (Michelena 1976 [1961]: 144n11), repetía: "La pronunciación antigua debió ser -añ, -eñ, como en suletino, a juzgar por grafías como Assieng, año 1110, Beeriang 1097, Machirreng 1098 [...], lo mismo si se parte de lat. -anum que del gen. -ani".

El acierto interpretativo queda amenguado por romper implícitamente la continuidad fónica ("durante la Edad Media", "pronunciación antigua") sin indicar cuál fue su evolución posterior, sin constancia del paso siguiente ${ }^{39}$; más la injustificada indiferencia entre -anum y $-a n i^{40}$.

16. Entre las varias fuentes de vocal $a$ seguida de nasal palatal, la única posible como elemento derivativo ${ }^{41}$ es -(I)ANEUS ${ }^{42}$, según espero probar con los

${ }^{38}$ Anoto. La cita procede de Aymeric Picaud, Liber Sancti Iacobi, cap. VII.

${ }^{39}$ También Andersson (1963: 223) parece admitir distinta pronunciación entre -aing, palatal, y -ain.

${ }^{40}$ Disiento de la exposición de Ramírez Sádaba (1988: 187), según el cual "-ain funciona como un sufijo genuinamente vasco para formar topónimos cuya base es un apelativo". Desde el siglo XI, también sobre antropónimos latinos, añadido directamente a la consonante o mediante la vocal - $i$-. Opina que "-ain sigue siendo un sufijo vigente, y las grafías -ang/-eng no representan formas palatalizadas distintas de -ain/-ayn". Las diferentes grafías de la documentación medieval — continúa - no corresponden a diferencias fonéticas: en un mismo año (Leyre, 1110), Badozteng y Badoztain son debidas a diverso escribano, según consta por su respectivo nombre, o "a una pronunciación algo distinta". Acepta, con Michelena, partir del genitivo.

${ }^{41}$ Comp. con nav. castagne, estraynño, montanna, etc., antes citados; también con sus cognados cast. y con los cat. CALCANEU > calcany, EXTRANEU > extrañ, SUBTERRANEA > soterranya, y, probablemente, IOHANNEU > Jubany.

${ }^{42}$ Apenas cabe detenerse en el origen (controvertido, pese a su alta frecuencia en latín y en su continuidad románica) de los sufijos aquí tratados. Apunto breves datos que aclaran su vario comportamiento. Pisani (1962: 152) ve la adjunción del sufijo -no a temas en -a (Roma-nus) como origen de -anus, pronto productivo (Luc-anus). Leumann (1963: 207), para quien -aneus (Galbaneus, Herculaneus) es de "Ausgangspunkt unbekannt", menciona poco antes -eus, aplicado a antropónimos para formar adjetivos (Apollineus, Caesareus). Obviamente, hubo un cruce entre ambos sufijos. Según Morano (1978: 759), inicialmente -anus solo fue productivo con topónimos (Romanus, Albanus). Después, abundaron los cognomina en -ianus formados sobre gentilicios en -ius (Lucianus, Marianus), extendido luego a temas distintos (Caesarianus, Chistianus). Para Kajanto (1965: 130), -ianus apenas excede en frecuencia a -ius, con el que se funde (Asci-ianus, Aureli-ianus). En OLD (s. v.) se considera -anus prolongación de -nus, origen a su vez de -ianus (Catullianus) y de -aneus. Meyer-Lübke (1890-1906: II, 537), cuyo testimonio elijo, pues notifica su presencia en varias lenguas románicas (fr. prochain; it. anziano; esp. liviano; etc.), lo entiende como "procedente irregular" de -anus, en competencia con él. Aunque tanto en la sincronía latina como en su descendencia -anus -ianus y -aneus -ianeus son dos sufijos diferentes (Fernández Ramírez, 1986: 43; Wandruszka, 2004: 388), con frecuencia el segundo no figura aparentemente en superficie, por pérdida del componente palatal, encubierto por el primero. De ahí la dificultad para delimitar sus constituyentes. En español es patente si el primero acaba en consonante: azoriniano, becqueriano, cidiano, hitleriano. No lo es en ambrosiano, bacteriano, colombiano, diluviano. 
mismos topónimos, como piedra de toque, escogidos por Michelena ${ }^{43}$, y les añado documentación ${ }^{44}$. Acepto, pues, sus bases, con observaciones o nuevas propuestas, si procede; bien entendido que mi atención primaria recae sobre el sufijo ${ }^{45}$. Confío en mostrar, posteriormente, que hubo un cambio de pronunciación, cuya causa no fue sino una lectura castellanizante o, simplemente, actualizada de <-áin>.

\section{AMALÁIN}

Amalayn, 1231, 1237, 1601...

AEMILIUS $\rightarrow$ Aemilianeus $>$ Aemillaño $>$ por disimilación de palatalidad, Emilaño, grafiado finalmente, con algunas variantes, como Amaláin, forma causante, por su escritura, de un nuevo cambio fonético, según he anticipado poco antes y luego explicaré $(\S 18)$.

Posteriormente habré de ocuparme $(\S 17)$ de la apócope vocálica, común a todos los topónimos analizados tras el presente.

Aemilianus (Kajanto, 1965: 32 y passim); Aemilianius (Solin y Salomies, 1988: 7), Aemillianus (Solin y Salomies, 1988: 289).

No cabe silenciar la evolución de las dos primeras vocales. De la inicial cabría esperar su conservación o pérdida; de la segunda, su conservación (cfr. infra Amatriáin). Así, en los derivados que recoge Menéndez Pidal (1968: 138), entre ellos el muy frecuente Millán. Ramírez Sádaba (2002: 41) propone un antropónimo no latino, Amala, datado en 1350 (no figura en Abascal, 1994, ni lo he identificado; pero cfr. infra). El latín Amalius salvaría las dificultades señaladas; pero, por cuanto se sabe de su historia, lo descarto.

Merece mencionarse el doblete Amillano, con sufijo -ANUS, a $50 \mathrm{~km}$. de Pamplona, en el centro oeste de Navarra.

\section{AMATRIÁIN}

Amatriayn, 1280, 1366, 1591, 1600; Amatriain, 1600, 1700, 1713. 1723, 1855, 1885, 1892...; Amatrain, 1495.

EMETERIUS $\rightarrow$ Emeterianeus $>$ Emetriaño, grafiado finalmente Amatriáin. Este topónimo y Maquirriáin ( $c f r$. infra) son, entre los analizados, los únicos en que aflora -ian $(o)$.

Emeritianus (Kajanto, 1965: 351).

Para los cambios, compartidos por Amaláin, que permanecen sin denunciar,

${ }^{43}$ Michelena incluye también el topónimo Domezain, suletino, como él mismo apunta, inexistente en Navarra, aunque en esta se testimonien Domitius y Domitia.

${ }^{44}$ Mis fuentes principales son $T C N$ y $O V$.

45 Por esa razón no me entretengo en puntualizar los cambios regulares, tanto vascuences como romances, que, a veces, se muestran ambos coexistentes en un mismo topónimo. Tampoco, en destacar grafías típicas navarras para $/ \mathrm{ka} /, / \mathrm{ga} /, \mathrm{go} /$. 
cabría suponer una causa común, preferentemente quizá un fenómeno de inducción léxica ${ }^{46}$. Sobre su identificación, no presento propuestas autorizadas, que exigirían un estudio particular, ajeno a la finalidad presente, de su base derivativa, sino hipotéticos modelos operativos. Uno, *AMA, admitiría, en principio, ser el vasc. ama, 'madre', en alguna de sus acepciones secundarias o figuradas, presentes en sintagmas como Ama Nafarra, Ama Sarracinaz (citados por Michelena, en el Cartulario de San Millán) o, menos congruente, Ama Eliza. Otro, correspondería al primer componente de los antropónimos visigodos dúplices: Amala-godus, Amala-redus, Amala-ricus, mencionados por Piel y Kremer (1976: 72) ${ }^{47}$.

Por otra parte, el paso E $>a$ ocurre también en (ECCLESIA) SANCTI EMETERI $>$ Santander.

\section{ANSOÁIN}

Sansoayn, 1240, 1268 1270, 1275, 1350, 1628; Sansoaynn, 1268; Sansoain, 1628, 1724; Ansoain, 1628, 1736, 1784, 1829, 1927...

ANSO $\rightarrow$ Ansoaneus $>$ Ansoaño, grafiado finalmente Ansoáin. Actual pronunciación popular según varias fuentes toponímicas, Ansuáin, como cabía prever.

Michelena reconoce que la base es poco clara, como asimismo la alternativa inicial $a-\sim s a-$.

\section{ASTRÁIN}

Asterayn, 1275, 1595, 1665; Astarayn, Aztarayn, 1280, 1663; Azterayn, 1565, 1569; Astrain, 1700, 1702, 1704, 1708, 1717, 1723, 1804, 1825, 1880, 1892...; Astrián, 1892.

ASTER $\rightarrow$ Asteraneus $>$ Astraño, grafiado finalmente Astráin.

Astranius (Solin y Salomies, 1988: 24).

No indica Michelena la procedencia de la base, ausente en los repertorios de ( $\operatorname{cog}$ )nomina latinos. Como tal constituyente se adecuaría perfectamente Astura, 'nombre de un soldado' $(O L D)$, pero parece testimonio único. Se cono-

\footnotetext{
${ }^{46}$ De la evolución fonética incumplida en topónimos opina Pabón (1953: 163, precisamente a propósito del sufijo latino -ana > -ena, por acción de la imela): "Es natural que esto ocurra [...]: sobre los topónimos actúan sin duda una fuerza de conservación en ciertos medios y un impulso de desgaste en otros. Tienen de una parte un valor oficial y consagrado; de otra, un uso constante en boca de las gentes del pueblo".

${ }^{47}$ Hasta 10 nombres comenzados por la raíz Amal-: Amalsindo, Amalbertus, Amalfredus, etc., muy frecuente, Amalricus, más otros con Ama- y distinto final, probablemente todos germanos, recopila Bolòs i Masclans (1994, s. v.). No descarto la presencia de propietarios visigodos o, mejor, con nombre visigodo, que lo dieran a algún fundus o uilla. Recuérdese, al efecto, que Pamplona, donde el año 642 fue coronado Chindasvinto, tuvo guarnición visigoda.
} 
cen aster, asteris, 'astro', y, raro, aster, asteri, 'nombre de una planta'. Pese a su identidad formal con Aster, estimo más adecuado partir, mediante -ANEUS, de cualquiera de las siguientes formaciones: ASTERIUS, bien documentado: 2 veces en la Galia Cisalpina; 1, en la Galia Narbonense; 3, en Dalmacia, según Mócsy (1934, s. v.). Kajanto (1965, s. v.), registra Asturius, 3 veces en Hispania. Astranivs figura en una inscripción alicantina (Abascal, 1994, s. v.). Frente al étimo propuesto por Michelena, me inclino por la última forma citada como primer estadio evolutivo, que, tras la derivación, pierde la vocal intertónica.

\section{BARBATÁIN}

Barbatayn, 1100, 1628, 1630; Barbatan, 1100; Barbatain, 1167, 1198, 1247, 1603, 1659, 1702, 1888...; Barbatanh, 1275,1276; Uaruatyn, 1630.

BARBATUS $\rightarrow$ Barbataneus $>$ Barbataño, grafiado finalmente Barbatáin.

Barbacianus, Barbanus, Barbatianus (Kajanto, 1965: 142 у passim).

\section{BELASCOÁIN}

Blascoan, 1216; Blasquoain, 1242; Blascoayn, 1257, 1278, 1471, 1532; Blascoanh, Blascohan, Blaschoayn, 1271-1277; Belascoayn, 1359, 1622; Blascoain, 1366, 1566; Berascoain, 1574; Berascoayn, 1576; Verascoayn, 1576; Belazcoayn, 1591; Belasquayn, 1764; Belascoain, 1770...

Bien conocida la base vascuence bela, 'cuervo', incrementada con el sufijo diminutivo, asimismo vascuence, -sko, la evolución habrá sido: BELASCO $\rightarrow$ Belascoaneus > Belascoaño, grafiado finalmente Belascoáin.

\section{GARZÁIN}

Guarçayn, 1366, 1727; Garzain, 1744, 1757, 1884.

GARCIA $\rightarrow$ Garcianeus $>$ Garciaño $>$ Garçaño, grafiado finalmente Garzáin.

\section{GUENDULÁIN $^{48}$}

Guentulain, 1092; Ganduleng, Guenduleng, 1105; Guendulain, 1268, 1366, 1654. 1691, 1714, 1889...; Guendulayn, 1268, 1280, 1366, 1428, 1532, 1591; Guendulan, 1274; Gandulayn, Gandulanh, 1277, 1279; Guandulay, 1280; Guindulain, 1654; Guenduloain, 1711, 1771.

CEnTUlus $\rightarrow$ Centulaneus $>$ Guendulaño, con disimilación de palatalidad, grafiado finalmente Guenduláin.

También el caso presente muestra evolución románica y vascuence (sonorización de la consonante inicial).

\footnotetext{
${ }^{48}$ Dos lugares (en Odieta, Esteríbar) comparten el nombre. Para la cuestión presente, sumo, sin reparo, la documentación de ambos.
} 


\section{LAQUIDÁIN}

Lachidien, 1131; Laquidein, 1185; Laquedain, Laquedayn, 1249; Laquidayn, 1249, 1268, 1280, 1350, 1532, 1591, 1593; Laquitan, 1274; Laquitanh, 1276; Laquidain, 1704, 1888...; Laquiriain, 1723.

Acepto, en principio, como siempre, la base postulada, sin seguridad, por Michelena.

*LAQUIDE $\rightarrow$ Laquidaneus $>$ Laquidaño, grafiado finalmente Laquidáin.

Pero ante la apuntada incertidumbre sobre la base, propongo otra, que estimo mejor garantizada:

FLACCIDUS $\rightarrow$ Flaccidaneus $>$ Laquidaño, grafiado finalmente Laquidáin. Sobre la evolución del grupo inicial, comp. con Labiano (cfr. § 13n), lugar muy próximo a Laquidáin.

\section{MAQUIRRIÁIN}

Machirreng, 1098, 1279; Makirreng, 1098, 1279; Maquirriein, 1174; Maquiriayn, 1215, 1268, 1275, 1532, 1597, 1600; Maquerenh, 1279; Maquirriayn, 1366; Maquiriain, 1709, 1714, 1716, 1901.

MACER $\rightarrow$ Macerianeus $>$ Maciriaño > Maquiriain, grafiado finalmente Maquirriain. Este topónimo y Amatriáin (cfr. supra) son, entre los analizados, los únicos en que aflora -ian $(o)$.

Macer, Macrianus y Macrinianus (Kajanto, 1965: 244); Macerianus (Solin y Salomies, 1988: 109).

El paso $-e->-i$ - responde a la presencia de yod en la sílaba siguiente. Atribuyo la $\langle r r\rangle$ (presente, como dejo constancia, desde la documentación más temprana) a que, en posición final (Macer), la $r$ suele emitirse con más vibraciones en vascuence que en los romances próximos. El ortógrafo vizcaíno Pedro de Madariaga (Arratia, 1537), en su Honra de escriuanos (Valencia, Mey, $1565,108 r$ ), encolerizado con sus paisanos por no usar el vascuence, parece quedar satisfecho porque en esta lengua "únicamente tres letras" difieren por su sonido del latín y del vulgar. Entre ellas, -r: "Vna sola $R$, al fin de dicion tiene fuerça de doblada r: uaguer ['uger egin'], nadar; eder, hermoso; laster, presto". Navarro Tomás (1925: 631) garantiza el aserto: en Guipúzcoa, $-r$ efectúa dos o tres vibraciones, según el énfasis de la emisión. Peculiaridad patente en textos navarros, atestiguada por varios mss. del Fuero General: Anociuarr (Anocíbar), Esteriuarr (Esteríbar), Lombierr (Lumbier), etc. Estos primeros atisbos de caracterización me parecen suficientes para justificar el caso examinado.

\section{PATERNÁIN}

Baternayn, 1242, 1273, 1278, 1388, 1678; Paternaan, 1274; Baternanh, 1275-1279; Paternain, 1622, 1709, 1714, 1716...; Patarrayn, 1665; Paternayn, 1678. 
PATERnUs $\rightarrow$ Paternaneus $>$ Paternaño, grafiado finalmente Paternáin.

Paternus $^{49}$ y Paternius (Kajanto, 1965: 18 y passim); Paternianus (Solin y Salomies, 1988: 376).

Queda patente la dualidad articulatoria de la consonante inicial: el resultado sonoro, $B$-, propio del vascuence coincide con la evolución del topónimo en su adaptación árabe (cfr. $§ 7)$.

\section{ZURIÁIN}

Zuriain, 1090, 1716, 1814, 1892...; Çuriayn, 1268, 1366, 1428, 1532, 1591; Surianh, 1277; Çuriain, 1280, 1869.

Desde el vasc. ZURI, 'blanco', según propone Michelena, con unánime aceptación, la evolución habrá sido: Zurianeus $>$ Zuriaño, grafiado finalmente Zuriáin.

17. Ya advertí que en los topónimos recién analizados el único rasgo inesperado es la apócope de $-o$, inusual en navarro (como en castellano) tras cualquier consonante nasal (cfr. testimonios en $\S 15$ ).

Apenas cabría atribuirlo, en principio, a resultado de una degradación acentual, en el supuesto de que, originariamente, el topónimo hubiese precedido a un nombre común (ager, fundus, praedium, vicus, etc.), portador del acento del grupo. Sería un caso semejante al de los adjetivos proclíticos: algún(o), buen(o), etc., y del nombre de pila ante el apellido: Martín(o) Périz. ${ }^{50}$. Pero, en cualquier caso, no conozco ningún testimonio en que fundus vaya precedido por los topónimos examinados. Añádase que ni siquiera he podido documentar fundus $^{51}$, incluso entre los numerosísimos topónimos de esta condición aducidos por Caro Baroja (1945) para establecer su conocida hipótesis. A efectos de la cuestión sintáctica aquí suscitada, igualmente puede comportarse alguno de los recién citados hipónimos locativos, como también uilla, pese a su distinto género gramatical. Puesto que este último apelativo, a diferencia de los precedentes, está abundantemente explicitado, me valdré de él para la prueba sintáctica. No es necesario advertir que, aplicado a un nombre propio, de inme-

49 Bien atestiguado en toda Hispania (también en Navarra, Castillo, Gómez y Mauleón, 1981, s. v.), con numerosa descendencia, que consigné en $\S 6$.

${ }^{50}$ Circunstancias quizá concurrentes en barbián y rufián, que menciono aquí como casos, a mi parecer, de apócope vocálica de -ano. Me atrevo a imaginar que si Corominas, a propósito de dichas palabras, hubiese conocido la existencia de los correspondientes cognomina: Barbianus y Rufianus (Kajanto, 1965: 108 y 142; 27 y 145, respectivamente), su opinión sobre el étimo de ellas quizá no sería la insertada en su diccionario: origen caló (aunque siente su relación con barba) para el primero, y, tras prolongadísima disertación, lat. *Rufulanus para el segundo.

${ }^{51}$ Se ha aceptado de modo unánime, pero bien podría ser que algunos respondiesen históricamente a la condición de ager, praedium, etc. 
diato se supondrá antepuesto. Pero no faltan casos que atestiguan la colocación inversa. En la Reja de San Millán, según específica indagación del propio Caro Baroja (1980) figuran: Elheniuilla, Licenvilla, Lacervilla, Nubilla, Orvilla, Verantivilla (presente también en Leire, 1110, 1113), etc. Solo uno se localiza en Navarra: Oxenevilla, actual Genevilla ${ }^{52}$.

La parva cosecha obtenida desestima la presunción inicial.

Una nueva revisión de fuentes me permite dar por satisfactoriamente resuelta la dificultad advertida. Ahora, la revisión de antropónimos y topónimos contenidos en la documentación del Monasterio de Leire (no lejano del ámbito más denso de los terminados en -áin) descubre numerosos casos, con variada terminación nasal, que experimentan apócope: ocurre no solo en función del acento contextual, es decir, con preferencia en posición proclítica, sino con independencia de él, fuera de toda presumible dependencia acentual.

Presento una breve y significativa muestra, en la que aparecen algunos de los topónimos antes individualmente examinados: Fortunius (1049 y passim) Fortun Sanz, Fortun Çiriz (1046), Fortuin Sanz (1083); don Galician de Iaca (1095); casas de Lainu cum tota sua radice (1110) don Flain de Villanoua (1065), Lain Petriz (1097); Seinor don Castain (1120), Gastang in Morello (1136); Frontin de Bergua (1136 $\left.6^{53}\right)$; Pelegrino de Castellaza (1182) Pelegrin de Atrosillo (1136).

Topónimos. Habeas Arischano cum suos meschinos (1085) Garsi Arceiz de Ariscan (1094); Fortuniones de Zuriain (1090); uillam Makirreng (1098); Domin (1102, bis), Doming (1108-1120 y 1121), actual Domeño < DOMINIUM; Sexaginta mesuras in Eristain inter panem et uinum (1085), Meam dotem de Eriztain teneat (1085), Maiuelo de Eriztan (1085).

La proximidad de Leire al Pirineo oscense (el monasterio sostenía relaciones de vario tipo con Huesca, cuestión ya aludida) me ha movido a examinar esta otra área geolingüística (si es que no se trata de la misma).

En ella, Menéndez Pidal (Orígenes) señala que la apócope de - $o$ tras $n$ es más frecuente en el norte de Aragón que en castellano y dialectos occidentales: Castang in Biel (1118), Fortung Blasch (1156), Pedro Blasch (1157), Enneco Blasch (1157), Pedro Ordong (1172). Como se ve, la pérdida afecta al primer miembro de estos antropónimos, al segundo o a ambos. En efecto, estos antropónimos apocopados se utilizan luego con independencia de su contexto fónico, lo cual demuestra que no ocurrió en relación con el acento o que la solución condicionada tuvo suficiente firmeza para perdurar luego libre de todo condicionamiento, como luego ejemplificaré.

\footnotetext{
${ }^{52}$ En Urroz-Villa (Navarra, así figura oficialmente), el segundo componente parece responder a una tardía concesión real.

${ }^{53}$ Este documento, original, del que vuelvo a citar otro testimonio, está expedido en Huesca.
} 
La apócope afecta incluso a los apelativos con función toponímica: Pin $(o)$ $\operatorname{Sec}(o)$ (1125). El topónimo Plan(o) responde a la fisiografía del lugar. La reconsideración de la apócope de -o (también tras otras consonantes que - $n$ ) permite a Menéndez Pidal concluir que parece característica propia del dialecto primitivo.

Todavía cabe ensanchar razonablemente la zona investigada con un salto transpirenaico. Dejaré, pues, constancia de que el gascón conserva, modificada o no, la vocal -o final tras nasal en el léxico general (Rohlfs, 1970: 436), mientras que los topónimos derivados con -ANUM la pierden (Rohlfs, 1970: 26). Ausente la mención de -ANEUS): Biran (Birius), Cadiran (Catirius). Todas las bases presentadas por Rohlfs, si son antropónimos latinos, presentan la terminación -ius.

Estimo oportuno recordar aquí que la forma apocopada de muchos antropónimos (cuya procedencia se remontará a una variada concurrencia) acaba imponiéndose en el español moderno, como nombre de pila o como apellido: Castán, Esteban, Fortún, Martín, Millán, etc.

18. La pronunciación última de los topónimos aquí examinados y de todos sus congéneres muestra, como queda dicho, que el segmento estudiado sufrió la despalatalización de su consonante y la conversión del grupo vocálico (dígrafo) en diptongo. Resulta más fácil y concluyente explicar la razón del cambio que señalar cuándo se produjo (obviamente, me refiero a sus primeras manifestaciones y a su consumación).

La despalatalización de ain, ayn debió de ocurrir en época muy temprana, pues, como vengo insistiendo, / $\mathrm{n} /$ final no figura en el inventario léxico navarro, al igual que sucede en castellano.

Falta información suficiente (y difícilmente alcanzable) para negar que una inmensa mayoría de la población navarra siguiese pronunciando la palatal. Sin embargo, el temprano abandono de las grafías más distintivamente palatales antes expuestas ( $g n n, n g, y g n, y n n, y \tilde{n})$ quizá apunte a una tendencia declinante en esa dirección.

Por otra parte, el Reino de Navarra, a partir de su unión con la Corona de Castilla, integraría en su burocracia funcionarios de formación idiomática castellana. Aunque, como queda expuesto, la grafía $\tilde{n}$ distaba de ser extraña en la escritura de los organismos navarros, la presencia de los nuevos componentes, en quienes $\tilde{n}$ gozaba de más profundo arraigo, hubo de abocar progresivamente a incrementar su empleo. De modo especial, esa relación operaría en los niveles superiores de las instituciones públicas, desde las cuales se propagaría, por su natural prestigio, a estadios administrativos inferiores y locales como mera imitación del modelo superior. Cuando las Cortes de 1538 lamentaban que los documentos estaban puestos en tal estilo que apenas se podían entender, su remedio se buscaría en el castellano. 
Por su parte, los escribanos, ante las exigencias de su oficio, mantendrían "a la letra" en la redacción de los documentos la forma consuetudinaria de los topónimos, a diferencia de lo que ocurría con los nombres apelativos. Práctica que se prolongaría hasta que la pronunciación originaria de áin como /'an/, insólita dentro del sistema gráfico moderno, gradualmente fuera abandonándose. Tal anomalía arcaizante acabaría cediendo, dado que $/ \mathrm{n} /$ se representaba, valga repetir, por $\tilde{n}$. A su vez, la terminación -ain, -ayn de los topónimos iría adquiriendo el valor fonético que tenía en el resto del léxico. Adviértase, además, que en el propio castellano entre ain y ayn no existía diferencia fónica alguna ${ }^{54}$.

La lectura, viva voce, de documentos públicos y privados, constituía el único medio para que los iletrados, mayoría de la población, llegasen a su conocimiento. Volveré sobre este aspecto de la recepción lingüística, pero anticipo ya, con el mismo propósito, la misión desempeñada por la figura del pregonero, que alcanza hasta tiempos presentes.

Por ese conducto se contribuiría a propagar entre toda clase de personas la nueva pronunciación de /'ain/ para los topónimos, prestigiada precisamente por el propio medio de comunicación.

Por cuanto queda expuesto, cabe conjeturar que mucho antes del siglo XIX la pronunciación /'ain/ estaba ya generalizada. Patentes testimonios de ella son, a comienzos de dicho siglo, los diccionarios geográficos e históricos de la Real Academia de la Historia (1802), Miñano (1826-1829), Yanguas (1840, archivero del reino de Navarra) y Madoz (1845-1850, basado en informantes navarros), con copiosas entradas de topónimos en -áin, ausente cualquier otra variante de esta grafia ${ }^{55}$.

La explicación expuesta para el cambio de pronunciación de -áin acabó también triunfando entre los habitantes de los lugares denominados con los topónimos en cuestión. Sin embargo, el mayoritario analfabetismo de ellos (aun sin reparar en su presumible condición de euskaldunes) y la natural fidelidad a mantener su propia tradición gentilicia no permiten aplicar aquí la causa antes expuesta para la lengua escrita.

Por esta razón me detengo en explanar por qué vía alcanzó a cambiarse la pronunciación tradicional de los topónimos.

\footnotetext{
${ }^{54}$ Recuérdese que Nebrija, ni en su Gramática ni en sus Reglas de Ortografía, mencionaba la $y$ como letra, pues "no se emplea por sí misma sino por $i$ ". La Ortografía académica, siempre favorable, con indecisiones, a la $i$, en 1754 (2. ${ }^{\text {a }}$ ed.) dictamina: "Cuando la $i$ se pronuncia unida con la vocal que le precede, se usa de la I latina, conforme a la práctica común y constante" (aserto este último muy discutible, por un tradicional uso de $y$ ).

${ }^{55}$ Quede claro que, en la cuestión examinada, no atribuyo ninguna influencia inmediata a estas obras en la cuestión examinada. Pero no estará de más recordar que Suárez de Figueroa (Plaza universal..., Madrid, 1615, 119v) opinaba que en castellano las imprentas de Madrid suelen marcar la pauta ortográfica. Los siglos posteriores confirman esta opinión.
} 
19. Cualquier hablante siente de modo espontáneo — no costará admitirlo- que su denominación de la propia localidad es la genuina y rechazará la versión ajena como errónea y hasta aberrante, atentatoria contra una legítima tradición ("aquí siempre hemos dicho...") 56 . Ahora bien, no menos conservadora es la tradición jurídica escrituraria en sus formulismos y en el tratamiento de los nombres propios por cuanto estos constituyen señal de garantía identificadora de personas y lugares.

Los moradores de Amaláin, por ejemplo, pronunciarían durante siglos /ama'laj/ (aunque la persistencia de la palatal final no resulte muy propicia a los hábitos idiomáticos del vascuence $\mathrm{y}$, menos, del romance). A la vez, los escribanos y, a la par de ellos, en un segundo plano del mismo ejercicio, diversos profesionales (curiales, notarios, recaudadores, censores, emisarios, agrimensores, etc. $\mathrm{y}$, si procede, párrocos y maestros) siguieron escribiendo, según la pauta consabida, Amaláin. Situación prolongada hasta que, progresivamente, como queda expuesto, los letrados empezaron a pronunciar /ama'laj/, para acomodarse a la nueva pronunciación /'ain/, según lo venían practicando en cualquier posición (amainar, botaina, dulzaina, envainar, jofaina, ojizaino, plantaina, polaina, vizcaíno, saín (?), vaina, zaino, zaíno, etc.) ${ }^{57}$. Con esta articulación, diptongo seguido de nasal, lo "leerían" ante la mayoría, analfabeta, único medio para darle a conocer — valga repetir - las informaciones públicas y privadas que la afectaban. Permítaseme recordar la importancia que, de modo unánime, se confiere a este proceso de comunicación en los orígenes romances y su alcance interdialectal, especialmente favorecedor de la castellanización. También, como caso ejemplar, la distancia entre oralidad, tan evolucionada, del francés y su escritura.

Hubo de llegar un momento en que, dada su preeminente procedencia, la "forma prestigiosa" acabaría aceptándose, individualmente, por gusto o por presunción o por oportunidad o por necesidad, etc. Por último, terminaría generalizándose, de manera progresiva, su adopción entre la totalidad de la población, aún analfabeta, hasta convertirse en única admitida y repetida la pronunciación /'ain/ ${ }^{58}$.

El proceso expuesto está motivado en buena parte por exigencias legales o, simplemente, burocráticas, cada vez más apremiantes: todo ciudadano ha de identificarse de acuerdo con las exigencias de autoridades y fedatarios. De ahí las variadas motivaciones, poco antes enumeradas, para aceptar una pronuncia-

56 Reproduzco parcialmente un juicio de Pabón (1953: 163), antes citado por extenso, sobre los topónimos: "Tienen de una parte un valor oficial y consagrado; de otra, un uso constante en boca de las gentes del pueblo".

57 Dudo sobre si, a los efectos presentes, debe contar el esquema acentual de las palabras consignadas.

${ }^{58}$ Del mismo modo que se produjo, con el tiempo, una renuncia al sistema local o regional de pesos y medidas para acomodarse al dominante en un mercado más amplio. 
ción ajena a la propia y espontánea. Este proceso puede ocurrir en todo tiempo y lugar. Referido al español actual, cualquier hablante, en determinadas situaciones de la vida pública, ha de eliminar, por apremio o según su libre acatamiento, una marca articulatoria (ceceo, geada, etc.) denunciadora de regionalismo o rusticidad. Aunque, tras esa debida rectificación ocasional, voluntaria o forzada, como dejo indicado, recupere sus personales hábitos articulatorios.

Dígase lo mismo para el euskaldún, también por motivaciones de otra índole, ante la alternativa en distintos rasgos válidos, entre el batúa y su dialecto nativo y familiar.

Aporto a continuación, para ilustrar el proceso expuesto, variados testimonios reales de la interrelación entre sistema gráfico y sistema fónico.

20. Con la pretensión de iluminar mi precedente exposición, presento un caso coetáneo, perfectamente constatado. Mutatis mutandis, encierra una notable analogía con lo expuesto sobre la historia de -áin: la interacción entre oralidad y escrituralidad o, por mejor decir, la tendencia a salvar el antagonismo entre ambas modalidades comunicativas, a costa siempre de uno $\mathrm{u}$ otro contendiente. Lo ilustra de modo ejemplar una serie léxica catalana, varios de cuyos miembros son portadores precisamente del mismo sufijo aquí estudiado.

Palabras como Alemany, calcany, Capmany o estrany, terminadas oralmente, mediante el dígrafo $n y$, en consonante nasal palatal, se leen, espontáneamente, por un castellanohablante como terminadas en consonante nasal + vocal $i$. Similar comportamiento al que ha venido conociendo toda la diacronía de -áin.

Las páginas blancas de Telefónica registran para Barcelona (según Google, consulta 21 de noviembre de 2016) Galbany (Galbaneus, antes mencionado), como primer apellido, 32 veces; ausente, Galbañ. Para Alicante, la misma fuente, con igual disposición, registra 19 veces Galbañ; ausente, Galbany. Sin duda se ha pretendido (no sé si conseguido) salvar así la pronunciación tradicional, a costa de la también tradicional forma gráfica, que la comprometía, dada la adscripción mayoritaria al español de la demografía lingüística ciudadana.

En Navarra, la pronunciación cedió ante la escritura histórica, a propósito de -áin; en Alicante, la escritura cedió ante la pronunciación histórica, a propósito de $-n y$.

La toponimia navarra ofrece, cuando menos, un caso más complejo que, en mi opinión, corrobora cómo pueden producirse fenómenos de interacción entre oralidad y escrituralidad. MutiLOA ('¿la cabaña del mozo?'), núcleo de población atestiguado, al menos, desde el año 1002 en la documentación legerense, se conoce modernamente como Mutilva. La previsible evolución inicial a Mutilua ${ }^{59}$ queda ase-

\footnotetext{
${ }^{59}$ Comp. con Ansoáin, Garisoáin, etc., denominaciones oficiales, cuya actual pronunciación popular es Ansuáin, Garisuáin, según fuentes toponímicas.
} 
gurada por algunas fuentes toponímicas. Puesto que la letra $u$, en especial la manuscrita, se ha venido realizando, descuidada o indiscriminadamente, como и cuadrada, $<\mathrm{u}>$, o como $u$ de corazoncillo, $<\mathrm{v}>$, se suscitaba inseguridad sobre la realización vocálica o consonántica de la segunda $u$ del topónimo ${ }^{60}$. El resultado fue que prevaleció la segunda opción entre, obviamente, los letrados, desde quienes luego se generalizaría la articulación como consonante bilabial: la escritura se impuso. Inexplicable evolución, /o/ > /b/, si no se atiende a la escritura.

21. De admitirse la propuesta de mi estudio, merecería comprobarse si la secuencia -áin < -(I)ANUS se ha aplicado a bases vascuences, como parece y según sostienen algunos autores, con función de verdadero sufijo, de modo directo y extensivo. En caso afirmativo, -áin habría de incorporarse a las aportaciones desveladas por Echenique (2006: 36, y posteriores) sobre el fondo de las relaciones entre vascuence y romance, que revelan "la permeabilidad entre ambos sistemas". A ampliar y confirmar así esta facilidad de trasvase se han sumado estudios recientes, como el de Torrens Álvarez (2015) sobre el préstamo de nexos coordinantes latino-románicos, y el de Casado Velarde (2017) sobre la difusión del sufijo -teg(u)i en español actual.

$P$. S. Varias evoluciones arriba expuestas se están confirmando actualmente en la lengua hablada. Perteneciente al término municipal de Pamplona, muy alejado del núcleo urbano, existía el paraje, apenas conocido por falto de motivos, denominado Erripagain (lo traduzco por 'ribazo'. Su sufijo, -gain, es válido para seguir el comportamiento del segmento -ain). La rápida formación de un extenso barrio en dicho lugar ha suscitado la incorporación de su nombre al habla oral y a la escrita (publicidad con oferta de viviendas, rotulación de transporte urbano, etc.). Lo ha hecho con dos variantes: Erripagain(a) y Erripagaña. Así figuran en sendas páginas del Diario de Navarra (24.VIII.18, 11 y 24).

\section{BIBLIOGRAFÍA}

Abascal Palazón, Juan Manuel (1994): Los nombres personales en las inscripciones latinas de Hispania, Murcia, Universidad.

Álvarez Rodríguez, Adelino (2016): El testamento de san Genadio, Madrid, Bubok.

${ }^{60}$ En el "Discurso proemial de la Ortografía" que acompaña al Diccionario de Autoridades, la Academia recomienda, para distinguir por escrito ambos oficios, "usar de la regla ya comúnmente recibida" de sustituir, cuando es consonante, "U abierta o cuadrada por V cerrada, que llaman de corazoncillo". La Academia no volvió a tratar de esta dualidad en las varias ediciones de su Ortografía a lo largo del siglo XVIII ni en las posteriores Sin embargo, la calificación de "comúnmente" tardaría en ser realidad. 
Andersson, Lennart (1963): "Le suffixe -ain (-ein) dans la toponymie pyrénénne", Boletín de la Real Sociedad Bascongada del Amigos de País, 19, pp. 215-336.

Bolòs i Masclans, Jordi (1994): Repertori d'antropònims catalans, Barcelona, Institut d'Estudis Catalan.

Canellas, Vidal de (1956): Vidal Mayor, Gunnar Tilander (ed.), Lund, Ohlssons.

Caro Baroja, Julio (1945): Materiales para una historia de la lengua vasca en su relación con la latina, Salamanca, Universidad.

Caro Baroja, Julio (1958): "Los estudios geográfico-históricos sobre el País Vasco y la dialectología", Revista de Dialectología y Tradiciones Populares, 14, pp. 425-440.

Caro Baroja, Julio (1980), "La villa y el fundus en la Reja de San Millán", en Julio Caro Baroja, Historia general del País Vasco, San Sebastián, Haranburu, pp. 207-238.

Casado Velarde, Manuel (2017), "Sobre un préstamos sufijal del euskera al español: -tegui", Hesperia, 20, pp. 7-19.

Castillo, Carmen, Joaquiìn Goìmez Pantoja y M. ${ }^{\mathrm{a}}$ Dolores Mauleoìn (1981): Inscripciones romanas del Museo de Navarra, Pamplona, Príncipe de Viana.

Cooper, Louis (ed.) (1960): Liber Regum, Zaragoza, Fernando el Católico, 1960.

Corominas, Joan (1972): "De toponimia vasca y vasco-románica en los Bajos Pirineos", Fontes Linguae Vasconum. Studia et Documenta, 4 (12), pp. 299-320.

DGV/OEH = Luis Michelena (1987-2005): Diccionario general vasco/Orotariko euskal hiztegia, Bilbao, Euskaltzaindia.

Echenique Elizondo, M. ${ }^{\text {a }}$ Teresa (2006): "Historia lingüística vasco-románica: tareas acabadas y perspectivas futuras / Euskera eta inguruko erromantzeen arte harreman historikoak: eginak eta eginkizunak", Oihenart, 21, pp. 25-44.

Eugui, García de (1907-1908): Crónica general de España, transcripción de G. Eyzaguirre Rouse, [s. 1.], [s. n.].

Fernández Ramírez, Salvador (1986): La derivación nominal, Ignacio Bosque (ed.), Madrid, Real Academia Española.

Gago Jover, Francisco (ed.) (2013): Digital Library of Old Spanish Texts, Hispanic Seminary of Medieval Studies, <http://www.hispanicseminary.org/t\&c/fgn/index-es. htm>.

Gavel, Henri (1951): “À propos des toponymes basques en ain”, Gernika, 16, pp. 2-5.

Gorrochategui, Joaquín (1995): "La romanización. Aspectos lingüísticos", Antiqva, 6, pp. 1-11, $<\mathrm{http}: / /$ antiqua.gipuzkoakultura.net/pdf/gorrocha.pdf $>$.

Grafström, Ake (1958): Étude sur la graphie des plus ancinennes chartes languedociennes, Uppsala, Almquist.

Irigoyen, Alfonso (1977): "Algunas consideraciones sobre onomástica personal vasca”, Euskera, 12 , pp. 561-623.

Irigoyen, Alfonso (1987): "Sobre el origen de los patronímicos y de ciertos topónimos terminados en -ain, -ein, sul. -añe", en Alfonso Irigoyen, De re philologica linguae Uasconicae, Bilbao, [s. n.], pp. 193-207.

Kajanto, Iiro (1965): The Latin Cognomina, Helsinki, Keskuskirjapaino.

Kremer, Dieter (1990): "De antroponimia asturiana y leonesa medieval", Lletres asturianes, 36, pp. 7-12.

Leumann, Max (1963): Lateinische Laut- und Formenlehre, München, Beck.

Löfstedt, Einar (1956a [1928]): "Genetiv und Adjetiv", en Einar Löfstedt, Syntactica, 2.a ed., Lund, Gleerup, I, pp. 107-124.

Löfstedt, Einar (1956b [1928]): "Nomimativ und Vokativ", en Einar Löfstedt, Syntactica, 2. ${ }^{\text {a ed., }}$ Lund, Gleerup, I, pp. 91-106.

Madoz, Pascual (1845-1850): Diccionario geográfico-estadístico-histórico de España..., Madrid, Madoz y Sagasti.

Marouzeau, Jules (1970): Traité de stylistique latine, Paris, Les Belles Lettres. 
Menéndez Pidal, Ramón (1968): Toponimia prerrománica hispana, Madrid, Gredos.

Meyer-Lübke, Wilhelm (1890-1906): Grammaire des langues romanes, Paris, Welter.

Michelena, Luis (1955 [1952]): Apellidos vascos, 2. ${ }^{a}$ ed., San Sebastián, Biblioteca Vascongada de los Amigos del País.

Michelena, Luis (1957): "El genitivo en la onomástica medieval”, Emerita, 24, pp. 134-148.

Michelena, Luis (1973 [1952]): Apellidos vascos, 3. a ed., San Sebastián, Biblioteca Vascongada de los Amigos del País.

Michelena, Luis (1976 [1961]): Fonética histórica vasca, 2.a ed., San Sebastián, Seminario Julio de Urquijo.

Michelena, Luis (1988 [1956]): "Introducción fonética a la onomástica vasca", Emerita, 24, pp. 167-186, 331-352.

Miñano y Bedoya, Sebastián (1826-1829): Diccionario geográfico-estadístico de España y Portugal, Madrid, Imprenta de Pierart-Peralta.

Mócsy, Andreas, Reinhardus Feldmann, Elisabetha Marton y Maria Szilágyi (1934): Nomenclator Provinciarum Europae Latinarum et Galliae Cisalpinea..., Budapest, Institutum Archeologicum Universitatis.

Mohrmann, Christine (1961 [1948]): "L'adjetif et le génitif adnominal dans le latin des chrétiens", en Christine Mohrmann, Études sur le latin des chrétiens, 2." ed., Roma, Storia e Letteratura, II, pp. 169-175.

Morano Rodríguez, Ciriaca (1978): "Los sufijos latinos en -anus", en Actas del V Congreso español de estudios clásicos, Madrid, Sociedad Española de Estudios Clásicos, pp. 750-763.

Navarro Tomás, Tomás (1925): "Pronunciación guipuzcoana. Contribución al estudio de la fonética vasca", en Homenaje a Menéndez Pidal, Madrid, Hernando, III, pp. 494-653.

OLD = Oxford Latin Dictionary (1988): Oxford, Clarendon.

$O V=$ Onomasticon Vasconiae (1986-): Bilbao, Euskaltzaindia.

Pabón, José M. (1953): "Sobre los nombres de la villa romana en Andalucía", en Estudios dedicados a Menéndez, Pidal, Madrid, CSIC, IV, pp. 87-165.

Piel, Joseph M. (1948): "Nomes de «possessores» latino-cristâos na toponímia astur-galego-portuguesa", Biblos, 23, pp. 143-202, 283-407.

Piel, Joseph M. (1954): "Nombres visigodos de propietarios en la toponimia gallega", en Homenaje a Fritz Krüger, Mendoza, Universidad de Cuyo, 2, pp. 247-268.

Piel, Joseph M. y Dieter Kremer (1976): Hispano-gotisches Namenbuch: Der Niederschlag des Westgotischen in den alten und heutigen Personen- und Ortsnamen der Iberischen Halbinsel, Heidelberg, Winter.

Pisani, Vittore (1962): Grammatica latina storica e comparativa, 3. ${ }^{\mathrm{a}}$ ed., Torino, Rosenberg.

Ramírez Sádaba, José Luis (1988): "Vitalidad indígena ante el proceso de romanización: el testimonio de los topónimos en -áin", en Congreso de Historia de Euskal Herria, Vitoria, Gobierno Vasco, I, pp. 177-192.

Ramírez Sádaba, José Luis (2002): "Navarra: los colectivos sociales en la antigüedad", en V Congreso de Historia de Navarra, Pamplona, Eunate, III, pp. 21-53.

Real Academia de la Historia (1802): Diccionario geográfico-histórico de España, Madrid, [Imp. de la Viuda de D. Joaquín Ibarra].

Rius Serra, José (1947): Rationes decimarum Hispaniae (1279-1280), transc., ed. e índices, Barcelona, CSIC.

Rohlfs, Gerhard (1970): Le gascon, 2. ${ }^{\mathrm{a}}$ ed.,Tübingen, Niemeyer.

Salaberri Zaratiegi, Patxi (2000): “Acerca del sufijo toponímico -ain”, Fontes Linguae Vasconum, 32, pp. 113-137.

Salaberri Zaratiegi, Patxi (2011): "País Vasco y Navarra", en Emili Casanova (ed.), Toponimia hispánica. Origen y evolución de nuestros topónimos más importantes, Valencia, Denes, pp. 63-97. 
Salaberri Zaratiegi, Patxi (2012): "Topónimos alaveses de base antroponímica terminados en -ain, -egi, -eta (-keta), -ika, -iku (-iko), -inu, (-ina), -itu (-ita), -on”, Fontes Linguae Vasconum, 44, pp. 323-356.

Salaberri Zaratiegi, Patxi (2014): "Sobre el topónimo Barañáin/Barañain”, Euskera, 19, pp. 335339.

Schrijnen, Joseph (1981 [1932]): I caratteri del latino cristiano antico, 2. ${ }^{a}$ ed., Bolonia, Patron.

Solin, Heikki y Olli Salomies (1988): Repertorium nominum gentilium et cognomina Latinorum, Hildesheim, Olms.

Tarriño Ruiz, Eusebia (2009): "El adjetivo", en José Miguel Baños Baños (coord.): Sintaxis del latín clásico, Madrid, Liceus, pp. 251-272.

TCN = Toponimia y cartografía de Navarra (1992): Pamplona, Gobierno de Navarra.

Tilander, Gunnar (ed.) (1951): Fueros de la Novenera, Uppsala, Almquist.

Torrego Salcedo, M. a Esperanza (2009): "Genitivo", en José Miguel Baños Baños (coord.): Sintaxis del latín clásico, Madrid, Liceus, pp. 155-184.

Torrens Álvarez, María Jesús (2015): "Contacto vasco-románico y fases de un préstamo gramatical: el origen latino-romance de la coordinación vasca", Boletín de la Real Academia Española, 95, 547-566.

Touratier, Christian (1994): Syntaxe latine, Louvain-La-Neuve, Peeters.

Väänänen, Veikko (1967): Introducción al latín vulgar, Madrid, Gredos.

Wandruszka, Ulrich (2004): "Derivazione aggetivale", en Maria Grossmann y Frank Rainer (eds.), La formazione delle parole in italiano, Tubingen, Niemeyer, pp. 382-402.

Yanguas y Miranda, José (1840): Diccionario de antigüedades del Reino de Navarra, Madrid, Goyeneche.

Fecha de recepción: 23 de julio de 2017

Fecha de aceptación: 11 de diciembre de 2017 